\title{
Use of 2-aminoethanesulfonic acid (taurine) for cryopreservation and storage of Siberian sturgeon sperm
}

\author{
Konstantin Kovalev ${ }^{1, *}$, Olga Dokina ${ }^{1}$, Natalia Pronina ${ }^{1}$, Dmitry Balashov ${ }^{1}$, and Aleksandra \\ Krasilnikova ${ }^{2,3}$ \\ ${ }^{1}$ Branch for the freshwater fisheries of "VNIRO" ("VNIIPRKH"), 40a, Rybnoe, Moskovskaya oblast', \\ 141821, Russia, \\ ${ }^{2}$ Federal Research Centre the Southern Scientific Centre of the Russian Academy of Sciences, 41, \\ Chekhov str., Rostov-on-Don, 344006, Russia \\ ${ }^{3}$ Don State Technical University, 1 Gagarin square, Rostov-on-Don, 344003, Russia
}

\begin{abstract}
The research aimed to determine the effect of different taurine concentrations on the duration of sperm fertility preservation and the results of further use during cryopreservation. The taurine was injected into the sperm of the Siberian sturgeon by various methods under conditions of low positive temperatures. Immediately after preparation, the taurine was injected into native sperm at concentrations of $0.01,0.05$, and 0.1 $\mathrm{mmol} / \mathrm{ml}$. Two methods of introducing taurine into native sperm were tested: 1 (dry method) - adding taurine powder directly to native sperm and 2 (wet method) - adding taurine dissolved in saline to native sperm. The studies have shown that injections of taurine in an amount of $0.05-0.1$ $\mathrm{mmol} / \mathrm{ml}$ both dry and wet can be recommended as the method of longterm preservation of the native sperm of Siberian sturgeon viability. While storing Siberian sturgeon sperm for further cryopreservation the optimal taurine concentration is $0.01 \mathrm{mmol} / \mathrm{ml}$.
\end{abstract}

\section{Introduction}

One of the most important problems in the protection of biological resources and aquaculture is the preservation of the genetic diversity of aquatic organisms. This problem is relevant for rare and endangered fish species, and aquaculture objects as well [1-2].

Dramatic reduction of the natural reproduction of biological resources and the threat of a global ecological catastrophe (such forecasts appear more and more often) lead humanity to the evident conclusion that saving the animals and plants genetical fund is a strategically urgent task for the worldwide community and the Russian Federation.

Cryotechnologies make it possible to solve the problem of preserving genetic resources in a short time and provide unlike living collections a higher degree of representativeness of the conserved genetic material. The success achieved in the fish sperm cryopreservation

*Corresponding author: silur5@mail.ru 
allows solving the problem of the cryopreserved sperm banks creation for use in fish farming [3-6].

Nowadays in fish breeding practice during the artificial reproduction of various fish species and cryopreservation of fish reproductive products the question of developing simple and reliable methods for long-term preservation of the fertility of native sperm is becoming increasingly acute.

The preservation duration of the spermatozoa viability under the strict observance of obtaining sperm conditions largely depends on the storage temperature. It is known that high-quality semen of sturgeon fish species does not lose its fertilize ability up to several days when it's kept on ice. In practice, we are faced with the fact that preserving the sperm's ability to fertilize even for a day only by cooling to $1-4{ }^{\circ} \mathrm{C}$ is not always sufficient. This is most likely depend on the initial quality of the native sperm, the conditions of the producers keeping, and on the ecological situation in general.

A search is underway for substances that have a protective effect on spermatozoa in conditions of low positive temperatures that allow to maintain the energy reserves of spermatozoa during overexposure and transportation and, as a result, increase their fertilize ability, as well as suitability for cryopreservation.

Natural antioxidants limiting the activity of free radical oxidation processes include tocopherols, carotenoids, vitamins A, K, ubiquinones (coenzyme Q), ubichromenols (QC), flavonoids, amino acids [7-10].

Among these substances, that are functioning as antioxidants, the sulfoamino acid taurine plays a special role in the mechanisms of seasonal adaptation of fish to near-zero temperatures, accumulating in large amounts in the blood and organs before wintering.

It is known that performing numerous physiological functions in tissues, taurine successfully modulates them under a wide variety of conditions and pathophysiological conditions [11-17]. In addition to the antioxidant effect, which manifests itself in a decrease in the intensity of lipid peroxidation processes, taurine is involved in the protection of the membrane from structural and functional destabilization caused by low temperatures; by inhibiting the activity of caspases, taurine suppresses the processes of apoptosis. The property of taurine to perform the function of a membrane protector, participating in the protection of membranes from structural and functional destabilization, inhibiting apoptosis, maintaining $\mathrm{Ca}^{2+}$ homeostasis, or functioning as an antioxidant against polyunsaturated fatty acids may be manifested at low positive temperatures [18].

Fish semen contains a large amount of bound and free amino acids. According to various data, the qualitative composition of the amino acids of the fish sperm remains constant, while the quantitative composition changes depending on the season, the age of the producers, the ecology, and especially on the quality of feeding. A decrease in the quantitative content of amino acids leads to a decrease in reproductive capacity, and also, presumably, to a decrease in the cryo-resistance of sperm cells or a complete intolerance to the cryopreservation procedure [19-20].

Research on the pre-cryopreservation processing of fish sperm is of particular relevance during the cryopreservation of natural individuals, the conditions of growth, development, and maturation that are poorly studied for aquaculture objects kept with violations of the culture technology.

Since there are no express tests for determining the physiological and biochemical quality of fish sperm and determining the criteria for suitability for reproduction and cryopreservation, the concentration of taurine for introduction into the native sperm of various fish species to prolong the viability of spermatozoa can vary greatly.

The study aimed to determine the effect of different concentrations of taurine introduced into the sperm of the Siberian sturgeon by various methods under conditions of low positive 
temperatures on the duration of preservation of sperm fertility and the results of further use during cryopreservation.

\section{Material and methods}

The objects of research were the sex products of sturgeon fish reared at the Konakovo department (Tver region).

To identify the possible protective, antioxidant, and membrane-modifying effect of taurine on sperm fertility during long-term storage at low positive temperatures, test sperm samples at different time intervals (from 30 minutes to 3 days) were evaluated by mobility (activity), fertilize ability, and suitability to freeze. The percentage of motile spermatozoa was assessed visually under a microscope at a magnification of 300-400 times. Fertilization of eggs with experimental sperm samples was carried out in laboratory conditions on Petri dishes in triplicate. Native sperm without additives served as a control during fertilization.

The taurine preparation was injected into native sperm at concentrations of $0.01,0.05$, and $0.1 \mathrm{mmol} / \mathrm{ml} \mathrm{immediately} \mathrm{after} \mathrm{preparation.} \mathrm{Two} \mathrm{methods} \mathrm{of} \mathrm{introducing} \mathrm{taurine} \mathrm{into}$ native sperm were tested: 1 (dry method) - adding taurine powder directly to native sperm and 2 (wet method) - adding taurine dissolved in saline to native sperm. A taurine solution was prepared with a saline solution with a taurine concentration of $0.2 \mathrm{mmol} / \mathrm{ml}$. This solution was added in calculated amounts to native sperm until the required concentrations were obtained. The control in the experiments was native sperm without taurine.

Sperm was transported in a thermal bag with ice at a temperature of $4-5{ }^{\circ} \mathrm{C}$. Cryopreserved sperm was taken from the cryobank of Branch for the freshwater fisheries of the Federal State Budget Scientific Institution "Russian Federal Research Institute of Fisheries and Oceanography". Sperm samples were stored in cryostorage Cryo Diffusion (France) in liquid nitrogen for 7 days. Thawing of sperm was carried out in a water bath for $60 \mathrm{~s}$ at a temperature of $40^{\circ} \mathrm{C}$. Motility in the experiment was analyzed using an unpaired Student's t-test. Statistical significance was set at $\mathrm{p}<0.05$.

\section{Results and discussion}

The beginning of the research was an experiment on a mixed sperm from 3 males of Siberian sturgeon (A. baeri). Taurine was added to the native sperm immediately after receiving it from the male in an amount of 0.05 and $0.1 \mathrm{mmol} / \mathrm{ml}$ by the dry and wet methods, then it was transported in a thermal bag for 2 hours. The effect of the protective effect of taurine was assessed by motility after 2, 4, and 24 hours of storage (Fig. 1), and by fertilize ability and suitability for freezing after 4 hours of storage (Fig. 2). 


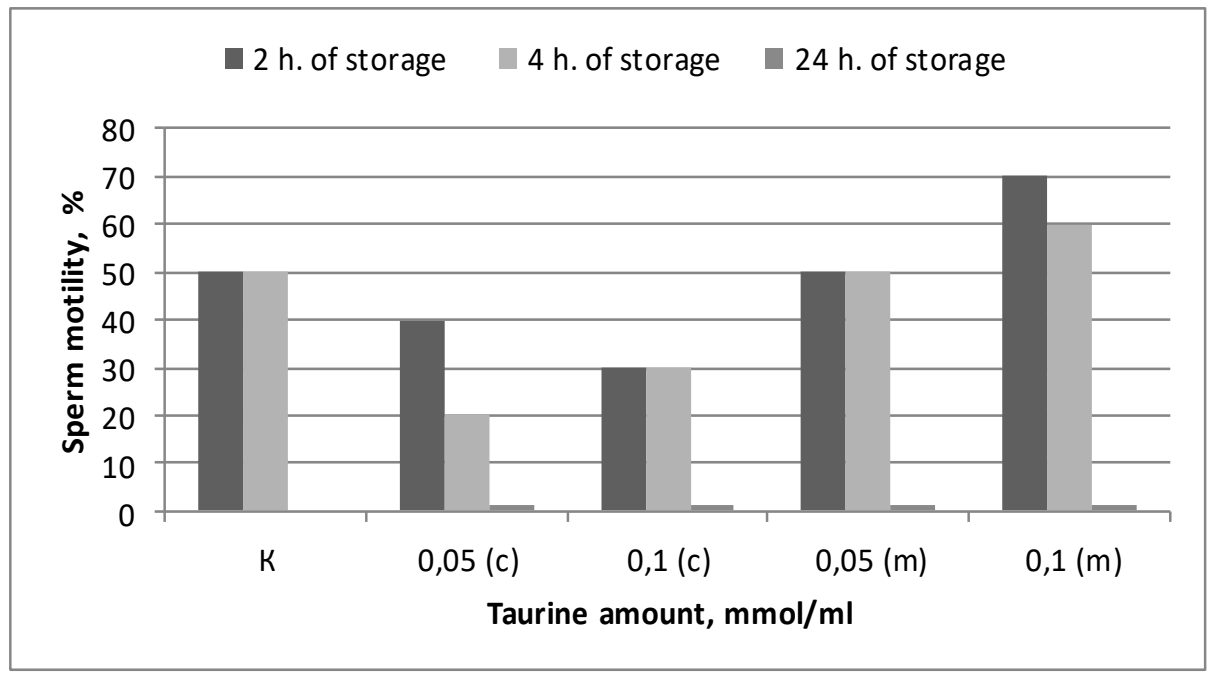

Fig. 1. Influence of taurine on the motility of spermatozoa of the Siberian sturgeon (A.baeri) during storage. Hereinafter: $\mathrm{K}$ - control, native sperm without taurine, $\mathrm{c}$ - dry route of administration, $\mathrm{m}$ - wet route of administration.

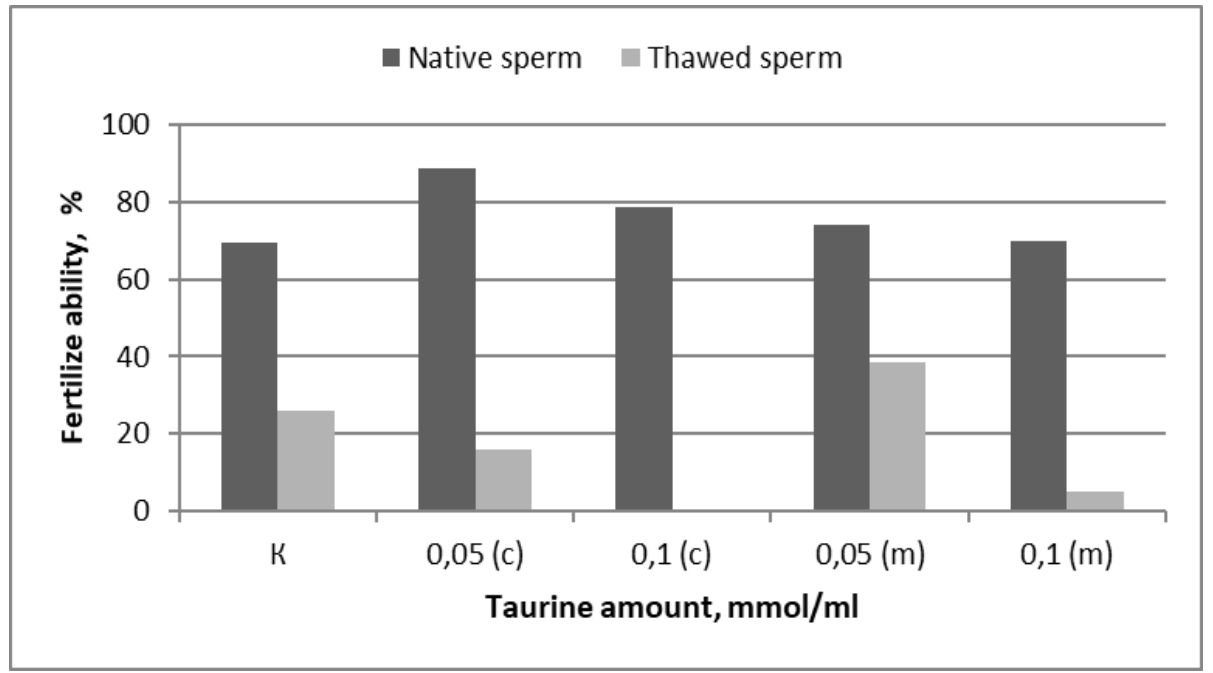

Fig. 2. The effect of taurine on the fertilize ability of sperm from the Siberian sturgeon (A.baeri) after 4 hours of storage and subsequent cryopreservation.

The wet method of taurine administration proved to be more effective, and the addition of $0.1 \mathrm{mmol} / \mathrm{ml}$ taurine by this method increased sperm activity by $20 \%$ (Fig. 1). After a day, sperm in both experimental and control samples was not suitable for continuing the experiment, although it should be noted that the samples with taurine had single motility, in the control sample the sperm was not activated.

The fertilize ability of all samples of native sperm with taurine after 4 hours of storage was higher than the control from 0.4 to $19.4 \%$. The most effective was the introduction of $0.05 \mathrm{mmol} / \mathrm{ml}$ taurine into the sperm by both methods dry and wet. The fertilize capacity of the test sample containing $0.05 \mathrm{mmol} / \mathrm{ml}$ taurine injected by the wet method, after cryopreservation, also exceeded the control one by $12.7 \%$ (Fig. 2). 
In the second experiment, the sperm of 5 male Siberian sturgeon (A. baeri) was used, with the mobility of native sperm from 70 to $100 \%$. The effect of taurine on sperm activity was assessed on a mixed sperm from 5 males; additionally, the effect of taurine was assessed individually on each male. Taurine was injected into the sperm mixture in two ways in the dry and dissolved form at two concentrations of 0.05 and $0.1 \mathrm{mmol} / \mathrm{ml}$, in individual semen samples - by the dry method in an amount of $0.05 \mathrm{mmol} / \mathrm{ml}$ (Table 1).

Table 1. The effect of taurine on the sperm fertility of the Siberian sturgeon (A. baeri) during shortterm storage.

\begin{tabular}{|c|c|c|c|c|c|}
\hline \multirow{2}{*}{$\begin{array}{l}\text { № } \\
\text { test }\end{array}$} & \multirow{2}{*}{$\begin{array}{c}\text { Taurine } \\
\text { concentration } \\
\text { in semen. } \\
\text { mmol } / \mathrm{ml}\end{array}$} & \multicolumn{3}{|c|}{$\begin{array}{c}\text { Mobility of native sperm after } \\
\text { storage. } \%\end{array}$} & \multirow{2}{*}{$\begin{array}{l}\text { Fertilize capacity of } \\
\text { native sperm after } 4 \\
\text { hours of storage. } \%\end{array}$} \\
\hline & & $4 \mathrm{~h}$ & $24 \mathrm{~h}$ & $48 \mathrm{~h}$ & \\
\hline $\mathrm{K}$ & - & 100 & 10 & 0 & 60.5 \\
\hline 1 & 0.05 & 80 & 20 & 0 & 63.4 \\
\hline 2 & 0.1 & 90 & 20 & 0 & 62.1 \\
\hline $1 *$ & 0.05 & 90 & 20 & 0 & 75.7 \\
\hline $2 *$ & 0.1 & 50 & 20 & 1 & 62.2 \\
\hline
\end{tabular}

$1 *, 2 *$ - wet route of administration.

While observing the motility of spermatozoa on a mixture of sperm for three days, it was found that in the first hours the addition of taurine to the sperm led to a slight decrease in cell activity. After 24 hours of storage, the sperm motility in all experimental samples with taurine was approximately two times higher than in the control.

The sperm activity in individual samples was significantly higher than in the mixed sperm from 5 males and on the third day in some samples, it was 70-80\%, while the sperm cells in the mixed sperm no longer moved (Fig. 3).

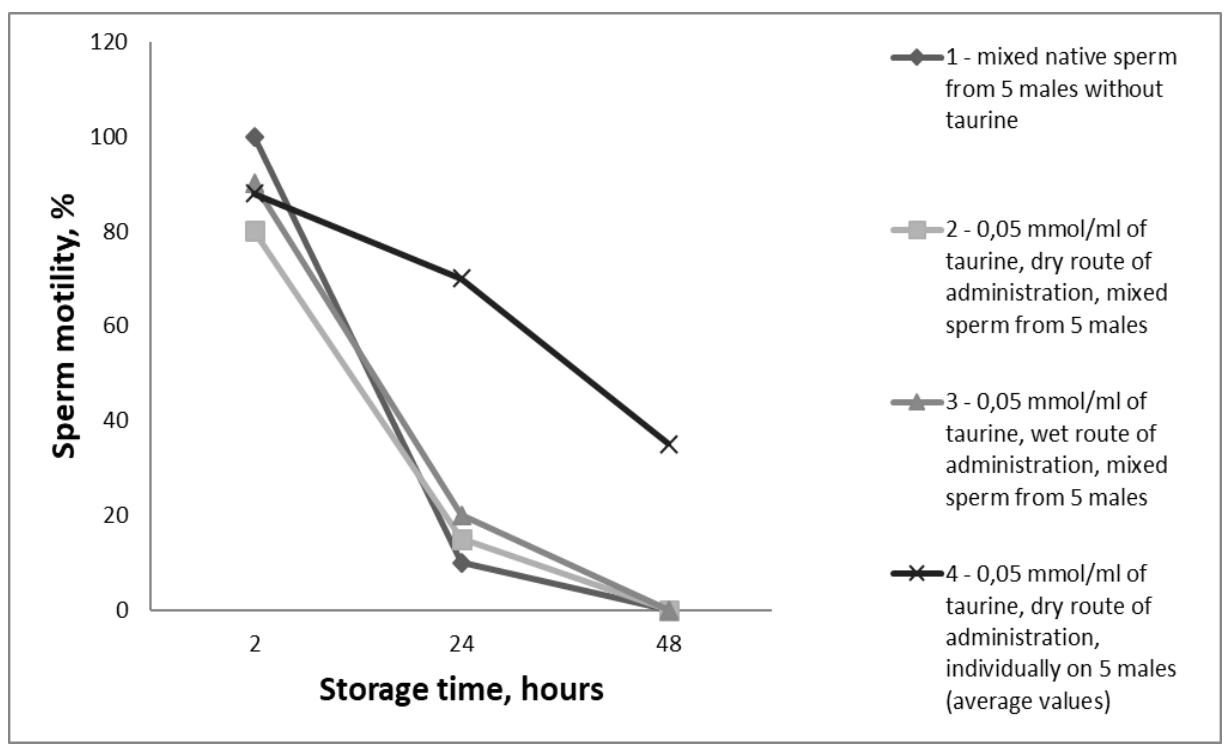

Fig. 3. The influence of taurine on the activity of sperm of the Siberian sturgeon (A. baeri) during storage 1, 2, 3 - the experiment was carried out on a mixed sperm from 5 males of Siberian sturgeons; 4 - the experiment was carried out individually on 5 males of Siberian sturgeons.

Fertilize capacity on the first day of storage, after 2 hours of equilibration at a low positive temperature of the experimental and control samples, both in the sperm mixture and in individual samples, did not have significant differences and amounted to about $60 \%$. 
An exception was a test sample with a content of $0.05 \mathrm{mmol} / \mathrm{ml}$ taurine introduced into sperm by the wet method, the fertilize capacity of which was $75.7 \%$.

Further studies were carried out on the semen of one male Siberian sturgeon. An additional taurine concentration of $0.01 \mathrm{mmol} / \mathrm{ml}$ was tested. The fertilize ability of the test specimens in comparison with the control after 1 hour of storage in the refrigerator tends to decrease, and already after 2 hours of storage, an inverse relationship is observed (Table 2). Sperm containing taurine in an amount of $0.01 \mathrm{mmol} / \mathrm{ml}$ after 2 hours of storage turned out to be more suitable for freezing than the control.

Table 2. The effect of taurine on the sperm fertilize ability of the Siberian sturgeon (A.baeri) during storage and freezing.

\begin{tabular}{|c|c|c|c|c|}
\hline \multirow{2}{*}{$\begin{array}{c}\text { No } \\
\text { test }\end{array}$} & \multirow{2}{*}{$\begin{array}{c}\text { Taurine concentration in } \\
\text { native sperm. mmol/ml }\end{array}$} & \multicolumn{3}{|c|}{ Fertilize capacity of sperm after storage.\% } \\
\cline { 3 - 5 } & & $\mathbf{1}$ hour & $\mathbf{2}$ hours & $\begin{array}{c}\mathbf{2} \text { hours of storage } \\
\text { and freezing }\end{array}$ \\
\hline $\mathrm{K}$ & - & 31.8 & 38.4 & 8.5 \\
\hline 1 & 0.05 & 30.4 & 34.3 & 10.8 \\
\hline 2 & 0.01 & 39.2 & 57.7 & 48.4 \\
\hline 3 & 0.1 & 24.4 & 36.9 & 0 \\
\hline $1^{*}$ & 0.05 & 36.6 & 45.0 & 5.3 \\
\hline $2^{*}$ & 0.01 & 28.9 & 31.1 & 31.4 \\
\hline $3^{*}$ & 0.1 & 18.4 & 43.3 & 0 \\
\hline
\end{tabular}

$1 *, 2 *, 3 *$ - wet route of administration.

The studies have shown that the introduction of taurine in an amount of $0.05-0.1$ $\mathrm{mmol} / \mathrm{ml}$ both dry and wet can be recommended as a way of long-term preservation of the viability of native sperm of Siberian sturgeon.

If the semen is stored for subsequent cryopreservation, then the taurine content of 0.01 $\mathrm{mmol} / \mathrm{ml}$ is optimal for the Siberian sturgeon.

The introduction of taurine in an amount of $0.01 \mathrm{mmol} / \mathrm{ml}$ into the native sperm of sturgeon fish can be recommended not only for overexposure and transportation of sperm but also as a pre-cryopreservation treatment, i.e. to improve the protective properties of fish spermatozoa.

Experiments have shown that native sperm of Siberian sturgeon with the addition of $0.05 \mathrm{mmol} / \mathrm{ml}$ taurine retains its biological properties better in individual samples than in a mixture of sperm of the same samples.

The data obtained are of great practical importance since it is usually less financially expensive to transport the obtained sperm from remote regions and farms than to bring equipment and all the necessary materials for cryopreservation to the collection site. Also, monitoring the quality of semen before preservation is also more convenient in an equipped laboratory.

The preservation of fish sperm in conditions of low positive temperatures using taurine can be recommended in aquaculture when transporting sperm for fish reproduction, breeding, and hybridization.

\section{References}

1. S. Martínez-Páramo, Á. Horváth, C. Labbé, et al., Aquaculture 472, 156-177 (2017) doi:10.1016/j.aquaculture.2016.05.042

2. K.V. Kovalev, N.D. Pronina, O.B. Dokina, V.A. Milenko, Cryobiology 85, 176 (2018) doi:10.1016/j.cryobiol.2018.10.213

3. A.A. Krasilnikova, A.M. Tikhomirov, Agricultural Biology 53(4), 762-768 (2018) doi: 10.15389/agrobiology.2018.4.762rus 
4. M.M. Belaya, A.A. Krasilnikova, Vestnik of Astrakhan State Technical University: Fishing Industry 1, 83-90 (2019) doi: 10.24143/2073-5529-2019-1-83-90

5. E.N. Ponomareva, A.N. Nevalenniy, M.M. Belaya, A.A. Krasilnikova, Vestnik of Astrakhan State Technical University: Fishing Industry 4, 118-127 (2017) doi: 10.24143/2073-5529-2017-4-118-127

6. A. Krasilnikova., E. Ponomareva, S. Shvedova, M. Magomedov, D. Rudoy, A. Olshevskaya, E3S Web of conference 210, $07010 \quad$ (2020) doi:10.1051/e3sconf/202021007010

7. Mohsen Ghaleb Al-Mutary, Journal of King Saud University - Science 33(1), 101226 (2021) doi:10.1016/j.jksus.2020.10.023

8. K. Neha, Md. Rafi Haider, A. Pathak, M. Shahar Yar, European Journal of Medicinal Chemistry 178, 687-704 (2019) doi:10.1016/j.ejmech.2019.06.010

9. V. Sindhi, V. Gupta, K. Sharma, et al., Journal of Pharmacy Research 7(9), 828-835 (2013) doi:10.1016/j.jopr.2013.10.001

10. A. Magdalena Pisoschi, A. Pop, European Journal of Medicinal Chemistry 97, 55-74 (2015) doi:10.1016/j.ejmech.2015.04.040

11. N.J. Mezzomo, B.D. Fontana, T.E. Müller et al., Hormones and Behavior 109, 44-52 (2019) doi: 10.1016/j.yhbeh.2019.02.006

12. N. Richard, R. Colen, C. Aragão, Aquaculture 468(1), 94-101 (2017) doi:10.1016/j.aquaculture.2016.09.050

13. M. Prideaux, Y. Kitase, M. Kimble, T.M. O'Connell, L.F. Bonewald, Bone 137, 115374 (2020) doi:10.1016/j.bone.2020.115374

14. W. Koven, O. Nixon, G. Allon, et al., Aquaculture 482, 137-145 (2018) doi:10.1016/j.aquaculture.2017.09.039

15. M. Izquierdo, D. Domínguez, J. Ignacio Jiménez, R. Saleh, C.M. Hernández-Cruz, M. Jesus Zamorano, K. Hamre, Aquaculture 498, 246-253 (2019) doi:10.1016/j.aquaculture.2018.07.010

16. R. Dehghani, A. Oujifard, M. Torfi Mozanzadeh, V. Morshedi, D. Bagheri, Aquaculture 517, 734795 (2020) doi:10.1016/j.aquaculture.2019.734795

17. N. Martins, A.F. Diógenes, Rui Magalhães, I. Matas, A. Oliva-Teles, H. Peres, Aquaculture 531, 735820 (2021) doi:10.1016/j.aquaculture.2020.735820

18. Chang-Hong Cheng, Zhi-Xun Guo, An-Li Wang, Fish \& Shellfish Immunology 77, 457-464 (2018) doi:10.1016/j.fsi.2018.04.022

19. E. Cabrita, S. Ma, P. Diogo, S. Martínez-Páramo, C. Sarasquete, M.T. Dinis, Animal Reproduction Science 125(1-4), 189-195 (2011) doi:10.1016/j.anireprosci.2011.03.003

20. S. Martínez-Páramo, P. Diogo, M.T. Dinis, F. Soares, C. Sarasquete, E. Cabrita, Cryobiology 66(3), 333-338 (2013) doi:10.1016/j.cryobiol.2013.04.001 